\title{
Modelling Potential Health Gains and Health System Savings Associated with Vaporised Nicotine Products in Canada
}

\author{
Pierre Emmanuel Paradis, Cristina Ruscio
}

Funding: This study was funded by an unconditional research grant from JUUL Canada Ltd. ("Juul"). Throughout the course of this project, the authors had complete freedom in developing, testing, and generating results with this model, as well as drafting this manuscript. Modeling expertise and informal peer-review feedback were provided to the authors by several researchers, including internal researchers working at Juul and external economists. All opinions and findings contained within this paper are strictly the authors.

Potential competing interests: The author(s) declared that no potential competing interests exist.

\section{Abstract}

Objectives: To model population-wide health and cost impacts of vaporised nicotine products (VNPs) use among Canadian adults 20 years and older from 2015-2095.

Methods: A multi-state lifetable model was used to project potential changes in life expectancy and health-system costs, overall and by province/territory. The simulated population was divided into 68 cohorts by sex, ethnicity, and 5year age groups. Each year, individuals could either remain in their current state, or transition to one of six smoking/vaping states. Input parameters were extracted or estimated using data from Statistics Canada and literature. Three scenarios were modelled to reflect a range of uncertainty: Status Quo ("SQ", VNPs commercialised as they are currently in Canada); No-Vaping ("NV", assuming VNPs never entered the Canadian market); and a Pro-Switching Policy ("PSP", assuming increased VNP prevalence).

Results: Compared to NV, SQ projected to increase life-years by 922,547, while PSP increased them further $(+718,137)$. SQ projected a C $\$ 39.0$ billion reduction in cumulative lifetime costs compared to NV; PSP would further reduce them by $\mathrm{C} \$ 30.4$ billion. Statistical variability was assessed using sensitivity analyses on input parameters, and Monte-Carlo simulations.

Conclusions: Accessibility to VNPs in Canada was projected to generate net public-health gains and health-system cost savings. These projected health and economic consequences are sensitive to assumptions about accessibility and use by adult smokers and may vary by type of policy environment.

\section{Introduction}

Vaporised nicotine products ("VNPs") are alternatives to smoking that may assist adult smokers in switching away from combustible cigarette smoking. While the long-term effects of VNPs cannot be known precisely, health risks associated to 
VNPs are believed to be substantially less than traditional tobacco smoking (Ratajczak et al. 2018; Stephens 2018). Public health authorities such as the National Academies of Sciences, Engineering, and Medicine (NASEM), Public Health England (PHE) note that vaping is significantly less harmful than smoking combustible cigarettes (McNeill et al. 2018; National Academies of Sciences, Engineering, and Medicine 2018). The difference in incremental risk of disease incidence between tobacco smoking and VNPs may contribute to improve health and cost outcomes, should use of the latter by current smokers increase.

Several population health models have evaluated the impact of introducing VNPs to market (Apelberg et al. 2018; Cherng et al. 2016; Levy et al. 2018; Levy et al. 2017; Warner and Mendez 2019). Among them is the Burden of Disease Epidemiology, Equity, and Cost-Effectiveness (BODE) model, a multi-state lifetable model that was developed by researchers at the University of Otago, Wellington (New Zealand) to evaluate the effectiveness of interventions aimed at reducing specific diseases and costs associated with health problems such as obesity and smoking (Blakely et al. 2016; Burden of Disease Epidemiology n.d.). A team of researchers, Petrović-van der Deen et al. (2019), hereafter designated as "NZ", adapted the BODE model to assess the health and cost impacts of legalizing the domestic sale of VNPs. The AppEco model presented here builds upon the core elements of the NZ cohort-based model and adapts it to the Canadian context on a national, provincial, and territorial level.

The AppEco model simulates whether the introduction of VNPs in the adult population may be associated with changes in health and cost impacts over the long-term. The objective of this study was to estimate the incremental gains in life-years and associated health system costs for various vaping versus smoking scenarios to determine the ways in which different policies can yield different health and healthcare cost outcomes. As Canada considers its current vaping regulations, it may benefit from a population health model that can inform future policy decisions.

\section{Methods}

The AppEco model, illustrated in Figure 1, was used to simulate the changes in incremental life-years lost due to SR diseases and health system costs for adults in Canada associated with varied levels of VNP use, at a $0 \%$ discount rate. Beginning in 2015, the AppEco model tracks, cohort by cohort, the health and cost impacts of VNPs on the selected population as they age. The model was developed using Microsoft Excel® to facilitate future research.

\section{Data Sources}

The main lifetable was built using data from Statistics Canada for demographics and all-cause mortality. The 14 SR diseases integrated into the model are those recognized by the Canadian government namely, cerebrovascular disease, chronic obstructive pulmonary disease (COPD), heart disease, as well as the following cancers: bladder, cervical, esophageal, kidney, laryngeal, lung, oral, pancreatic, pharyngeal, stomach, and leukemia. For each SR disease, the model integrated epidemiologic parameters for disease-specific incidence, prevalence and case-fatality rates, remission rates, direct and indirect health costs using a combination of data from Statistics Canada, the Public Health Agency of Canada (PHAC), and the Canadian Institute for Health Information (CIHI). Additional input data for smoking/vaping 
prevalence, transition matrices, and relative risks of SR diseases were estimated using data from the Canadian Tobacco, Alcohol and Drugs Survey (CTADS), as well as existing epidemiological literature. Data for each subset of the Canadian population aged 20 years or older in 2015 was collected, as it was the first year of reliable data collection on vaping in Canada. Where possible, provincial, and territorial-specific data was also integrated (see Table 1 for a full list of data sources).

\section{Study Population}

The study population was selected based on the number of Canadian adults aged between 20 and 99 years old in 2015 ( $n$ $=27,816,114)$. All rate and cost inputs in both the main lifetable and disease-specific lifetables for this population were divided into 68 cohorts separated by age, sex, and ethnicity (Indigenous and non-Indigenous). Each cohort is separated into five-year age groups from 20-24 years old to 94-99 years old.

\section{Smoking/Vaping Prevalence}

For each scenario, the prevalence of smoking and vaping was modelled from 2015-2095 by attributing the six smoking and vaping states listed in Table 2 to the study population. These states divide the population into Current Smokers Not Current Vapers (“CSNV"), Former Smokers Not Current Vapers (“FSNV"), Dual Users (“DU”), Former Smokers Current Vapers ("FSCV"), Never Smokers Current Vapers ("NSCV"), and Never Smokers Not Current Vapers ("NSNV").

\section{Smoking/Vaping State Transitions}

The AppEco model assumed that at every annual cycle, once a year, individuals can either transition to another smoking/vaping state or remain within the same state, depending on the scenario analysed. CSNVs can only transition to a FSNV, or DU state, as they cannot logically return to either of the two never smoker states. The same logic applies for DUs, who also cannot go back to a never smoker state. Unlike our never smoker states, CTADS definitions for vaping do not include a "Never Vaper State", but instead a "Not Current Vaper" state, thereby making the transition from current vaper to not current vaper states possible. As such, DUs can transition to CSNV and FSCV states, and NSCVs can move to a NSNV state. Based on the seminal work of Holford et al. (2014) for cross-sectional surveys of smoking prevalence across different age cohorts, which shows net decreases in prevalence after 20 years old, we assumed no uptake in smoking and conservative rates of cessation and transition to vaping.

Three transition-probability matrices were set for the following age cohorts: 20-44 years old, 45-64 years old, and 65+ years old; these were based on the findings of Holford et al. (2014) for CSNV smoking cessation rates, Zhu et al. (2017) for DU cessation rates, and Manzoli et al. (2017) for rates associated with CSNV to FSCV and DU to FSCV. We also assumed that the probability of DUs moving to a CSNV state (i.e., for DUs who quit vaping and go back to smoking alone) was equal to the probability of DU smoking cessation (Coleman et al. 2013-2015). All remaining transition probabilities were estimated using the residual sum of the initial probabilities.

Transition probabilities and resulting prevalence rates were estimated using Canadian smoking and vaping prevalence 
data for each state, as well as current baseline trends in smoking cessation rates. As transition rates remain constant throughout the simulation, smoking/vaping prevalence per state for each year (t) was obtained by multiplying the prevalence from year $\mathrm{t}-1$ by the corresponding state values of the transition matrices. See Figure 2 for a detailed account of the methods used for state transitions.

\section{Relative Risk}

The relative risk ("RR") of disease incidence for vaping and smoking was estimated by integrating transition rates from never, former, and current smokers/vapers, both to and from the regular use of VNPs. The RRs of SR diseases for current versus never smokers, and for former versus never smokers were expanded to include the RRs of vaping for those using VNPs. Drawing from the methods of the NZ study, the AppEco model used the results estimated by PHE and others to calculate the RR for the remaining DU, FSCV and NSCV smoking states.

According to Public Health England (PHE), vaping is $95 \%$ less harmful than smoking and dual use is $5 \%$ less harmful than smoking (McNeill et al. 2018). With respect to the NSNV state, which has no incremental risk of disease since there is an absence of both smoking and vaping, the RR for NSCV and CSCV was therefore attributed an incremental risk of $5 \%$ and $95 \%$ respectively. This does not imply that VNPs are safe to use. It is always preferable to refrain from any form of smoking and/or vaping.

Considering $R R_{S}=$ relative risk of disease for current vs non-smokers, and $R R_{F}=$ relative risk of disease for former vs nonsmokers, the relative harm associated with each state was estimated using the following calculations:

- $\operatorname{CSNV}=\mathrm{RR}_{\mathrm{S}}$

- $\mathrm{DU}=1+95 \%{ }^{*}\left(\mathrm{RR}_{\mathrm{S}}-1\right) ; 95 \%$ of incremental risk of CS vs NS

- $F S C V=R R_{F}+5 \%{ }^{*}\left(R R_{S}-1\right) ; F S$ vs NS risk plus $5 \%$ of incremental risk of CS vs NS

- $N S C V=1+5 \%{ }^{*}\left(R R_{S}-1\right) ; 5 \%$ of incremental risk of CS vs NS

- $F S N V=R R_{F}$

- $N S N V=1$; as there is no incremental risk of disease

The decline of relative risks over time (according to age and time since cessation) for former smokers were modelled using the equation developed and parameters estimated by Hoogenveen et al. (2008):

$$
=1+(R R-1) * \exp [-Y 0 * \exp (-\eta * \text { age }) * \text { timesincecessation }]
$$

This allowed for disease incidence to increase as the population ages, and decrease from the time individuals quit smoking, vaping, or both.

\section{Model Sequence}

Relative risks for each SR disease "RR $\mathrm{R}_{\mathrm{i}}$ ", with "i" representing one of the $14 \mathrm{SR}$ diseases, were used to calculate the 
population impact fraction (PIF). Calculating $\mathrm{PIF}_{\mathrm{i}}$ for each disease produces changes of incidence rates over time, which were then applied to the population lifetables:

$$
P I F_{i}=\sum p_{i}^{1} X R R_{i}-\sum p_{i}^{0} X R R_{i} / \sum p_{i}^{0} X R R_{i}
$$

where is the prevalence of smoking and non-smoking in the no-VNP scenario, and is the prevalence of smoking in other intervention scenarios.

Incidence of disease i after intervention $\left(1_{\mathrm{i}}{ }_{\mathrm{i}}\right)$ is

$$
l_{i}^{1}=P_{i} x\left(1-P I F_{i}\right)
$$

The $\mathrm{PIF}_{\mathrm{i}}$ determines the intervention base-case scenario incidence rates for all SR disease lifetables, which cause disease-specific changes in morbidity and mortality rates, as well as health system costs. Resulting incremental life-years lost and health system costs were then calculated for each annual cycle and across sex, age, and ethnicity cohorts for all scenarios. The difference in outcomes between each pair of scenarios established the measurable impact of each scenario.

\section{Outcome Measures}

Measurable outcomes included cumulative disease and mortality costs, as well as life-years lost due to SR diseases, which corresponds to the amount of years lost in an individual's lifecycle following death due to a SR disease between the ages of 20 and 85 years old. For example, if a man dies at 85 years old due to an SR disease, he gets attributed 1 year lost for not having lived his entire $85^{\text {th }}$ year; if a woman dies at 30 years old, her loss in life-years will be valued at 56 years. Moreover, the incremental social cost associated with each year of life lost was estimated and incorporated into the model. Using a meta-analysis conducted by Bellavance et al. (2009), we estimated that the value of a statistical life was approximately $C \$ 40,000$ per individual per year lived. This value was used to calculate the total incremental cost of life years lost due to SR diseases throughout the population's first 85 years.

\section{Scenario Analyses}

Health and cost outcomes for the following three scenarios were simulated:

- SQ Scenario: The SQ scenario assumes that VNPs are commercialised in Canada under the legal and regulatory constraints existing on August 1, 2019 (Government of Canada: Vaping product regulations n.d.). The transition matrices for each cohort under the SQ scenario used baseline smoking and vaping prevalence rates in Canada from 2015 to project the prevalence rates for subsequent years.

- NV Scenario:The NV scenario assumed the continuity of pre-2015 smoking trends without the introduction of VNP products to market. This scenario was simulated using the main lifetable until death (or 100 years old) as well as allcause mortality and morbidity rates. In this scenario, because VNP does not exist, the transition matrix used to project smoking and vaping prevalence over time only includes transitions for CSNV, FSNV and NSNV states. These 
transitions affect smoking prevalence in the years after 2015, and as a result, influence mortality, morbidity, and related costs over time.

- PSP Scenario: The aim of this scenario was to model the potential effects of an increase in Canadian VNP prevalence that could result from changes in the regulatory or policy environment. In the PSP scenario, Canadian vaping prevalence rates in 2015 were increased year after year to reach prevalence rates experienced in the United Kingdom (UK) in 2018, as a hypothetical model for this policy. The choice of UK was motivated by the fact that its regulatory environment encouraged adult smokers to switch away from smoking and towards lower-risk products, such as VNPs. Because of this policy orientation, we assumed that the overall prevalence of vaping would likely be higher in the UK than in Canada during those years. For cohorts where Canadian prevalence rates were already equal to or higher than UK prevalence rates, Canadian prevalence rates were used. For years 2019-2095, smoking and vaping prevalence rates evolve as they pass through the same transition matrix as in the SQ scenario.

\section{Sensitivity Analyses}

To account for the uncertainties surrounding the risk of vaping, sensitivity analyses included varying the 5\% (RR of vaping vs smoking) and $95 \%$ (RR of dual use vs smoking) assumptions of relative risk, to $10 \%$ and $25 \%$ and $50 \%$ (vaping vs smoking), and $70 \%$ and $100 \%$ (dual use vs. smoking) respectively.

The model ran Monte Carlo simulations $(n=1,000)$ for baseline risk ratios of each scenario for non-Indigenous men aged 30-34 years old. This cohort was chosen because (a) it has incremental costs of similarly high magnitude, but of opposite signs for each pair of compared scenarios (SQ vs. NV and SQ vs. PSP), as well as (b) a long modelling horizon (70 years). Consequently, the impact of parameter uncertainty should be most present for this cohort.

The model applied uncertainty to disease-specific RRs, as they are the single parameter that influences disease occurrence, probability of death and associated health care costs. The variable level of SR disease incidence RR was set for all cohorts in 2015 and carried over for each subsequent year of modelling. Published risk ratios included lower and upper bounds of confidence intervals, which allowed to approximate their distribution using log-normal distributions (Barendregt 2003; Olsson 2005).

\section{Results}

Table 3 presents the overall results of each scenario, as well as differences between SQ and NV scenarios, and SQ vs PSP scenarios. Compared to the NV scenario, the SQ scenario is associated with a $1.8 \%$ decrease in projected life-years lost due to SR diseases. This translates into 922,547 life-years gained, and an avoided social cost of life-years lost projected at $C \$ 36.9$ billion over the lifetime of all cohorts. NV is also linked with an estimated $C \$ 2.1$ billion in incremental health and mortality costs, mostly due to incremental health-system costs ( $C \$ 2.0$ billion). By contrast, under the PSP scenario, life-years lost due to SR diseases lowered by $1.4 \%$, increasing the absolute gain in life-years by 718,137 . Moreover, a total of $\mathrm{C} \$ 30.4$ billion in social cost of life-years lost, and total health and mortality costs were projected to be 
saved.

Figure 3 illustrates incremental costs by sex and ethnicity of the NV vs. SQ scenarios (3.a) and of the PSP vs. SQ scenarios (3.b). In Figure 3.a, younger cohorts of men were projected to reap the most benefits in terms of life-years gained and avoided costs. The increased projected benefits between 50-59 years old is related in part to the greater prevalence of vaping (single and dual use) compared to neighbour cohorts, which would shift towards smoking in the NV scenario. Under the PSP hypothetical, higher projected savings and life-years gained were associated with Canadian cohorts who in the SQ scenario use VNPs relatively less than their UK counterparts.

Compared to the NV scenario, non-Indigenous men were associated with a projected reduction (-1.9\%) in life-years lost due to SR diseases, or 569,097 life-years gained, and a C\$1.4 billion decrease in direct and indirect health costs under the SQ scenario. Under the PSP scenario, we projected an additional 1.6\% reduction in life-years lost, or 470,114 life-years gained, and a C $\$ 18.8$ billion reduction in total costs. Compared to the NV scenario, non-Indigenous women in SQ were associated with a lower projected reduction than men in life-years lost (-1.7\%) and in direct and indirect health cost savings (C\$659.7 million). Likewise, expected gains under the PSP scenario were lower than for non-Indigenous men $(+1.1 \%$ or 208,220 life-years gained, $-C \$ 429.9$ million in health costs). The overall benefits calculated for the Indigenous population, who represent less than $5 \%$ of the total population in Canada, are sizeable: 27,573 life-years and C\$1.1 billion in projected value of life-years gained already from the SQ scenario vs. the NV scenario, and 39,804 life-years and close to C \$1.6 billion in additional potential life-years gained under the PSP scenario. For all results by sex and ethnicity, see Table 4.

Statistical variability was assessed using sensitivity analyses on input parameters and Monte-Carlo simulations. Both analyses were performed on a single cohort, namely non-Indigenous men aged between 30-34 years old. Figure 4 presents the results of the sensitivity analyses conducted on life-years lost due to SR diseases. At baseline, the results for this cohort were the following: SQ vs. NV: -64,792 life-years lost, C\$156.8 million incremental direct and indirect health costs; SQ vs PSP: 49,332 life-years gained, -C\$134.0 million incremental direct and indirect health costs. When varying the relative risk of vaping vs. smoking, results consistent with our baseline inputs were noted, both in life-years lost or gained, and in incremental direct and indirect health costs.

Monte-Carlo simulations (Table 5) showed that every projected result using the mean value of inputs (first column) fell within simulated $95 \%$ confidence intervals $(\mathrm{Cl}$, third and fourth columns). For example, the 1,000 simulations project a $\mathrm{Cl}$ of $[-48,280 ;-82,993]$ for life years lost due to SR diseases in the SQ vs NV scenario, whereas the initially projected value was $-64,792$. Likewise, the Cls for total incremental cost (value) of both scenario pairs are [C $\$ 3,525$ billion; C $\$ 2,045$ billion] for SQ vs. NV and [-C\$1,562 billion; -C\$2,714 billion] for SQ vs. PSP. This confirms that even for cohorts with large cost values and a long projection horizon, the model's projections are stable and statistically significant across all projected outcomes. 


\section{Discussion}

The AppEco multi-state lifetable model was used to estimate potential changes in life-years lost and health-system costs associated to different levels of smoking and VNP use in the Canadian population alive in 2015. The SQ scenario was projected to contribute to a reduction in life-years lost and a substantial increase in healthcare system savings when compared to the NV scenario. These results were further reinforced in the PSP scenario, where both outcomes were projected to improve compared to the SQ scenario. The differences in life-years lost and health care savings between scenarios stem from demonstrated differences in health outcomes associated with smoking/vaping states. These results illustrate that scenarios with higher VNP use yield significant and positive outcomes compared to scenarios with lower levels of observed VNP prevalence, and hence higher smoking prevalence, in the study population.

These results are consistent with recent economic literature covering the health and economic impact of VNPs using a similar modelling approach. Using more extreme assumptions, Levy et al. (2018) projected that in the United States, the replacement of cigarette smoking by VNP use over a 10-year period would yield 6.6 million fewer premature deaths with 86.7 million fewer life-years lost in an "optimistic" scenario. In the NZ study, the legalization of VNPs was projected to augment 236,000 quality-adjusted life-years (QALYs) (95\% UI: 27,000 to 457,000) for the population alive in 2011 and save $\$$ NZ3.4 billion (95\% UI: 370 million to 7.1 billion; or $\$ 2.5$ billion in 2017 \$U) in health system costs.

Similarly, Warner and Mendez (2019) used a dynamic cohort model to project the effects of vaping on the US population over time. Under their base-case scenario, population-wide gains would reach approximately 3.3 million life-years by 2070. As a result, they found that health gains related to smoking cessation override SR disease losses that occur with VNPs on the market. Similar conclusions were reached by Cherng et al. (2016), who, using an agent-based model to project the effects of 7 hypothetical scenarios, found that VNPs generated substantially more population-wide changes in smoking cessation than initiation. They observed that VNPs would have to increase smoking initiation by more than $100 \%$ to have a noticeable impact on smoking prevalence. These patterns are consistent with the results of our model.

\section{Policy Implications}

The flexibility of the AppEco model, namely its ability to analyse health outcomes and costs between different VNP use level scenarios, can be informative for public health decision-making. Though the results of this study reflect the effects of smoking/vaping prevalence in the Canadian context, the model can also be used as a policy tool for different subsets of any population across a variety of health modelling topics, most notably in contexts where the distribution of the study population among subgroups varies from one time-period to the next.

This study has two main results. First, the use of VNPs in Canada may be associated with positive and significant health and economic outcomes compared to a counterfactual scenario in which smoking cigarettes would have been the alternative option. Secondly, these outcomes may be further improved with wider use of VNPs by adult smokers. Our research suggests that more attention should be given to the potential benefits of authorized VNP products on the health of Canada's adult smoking population and its health care system. 
Henningfield et al. (2018) commented that in failing to recognize the potential positive impacts of VNPs on population health, policymakers could be negatively impacting overall net health outcomes. The absence or delay of a policy recognizing the potential benefits of VNPs could lead to more deaths due to SR diseases and higher health system costs than a policy that would see wider prevalence of VNPs (Paradis et al. 2012). Our results also suggest that policymakers ought to consider the potential benefits of lower-risk products, such as VNPs, on adult population health when developing regulations on product use and access. They can also work to increase public awareness regarding the risks and potential benefits of these lower-risk products for current smokers. In Canada and elsewhere, awareness initiatives could help fill the information gap for adult consumers and improve health and cost outcomes accordingly.

The Canada-wide scenario analysis for Indigenous peoples suggests a positive potential for this population. Tobacco smoking prevalence in Indigenous populations across Canada is markedly higher than that of non-Indigenous people, further exacerbating the discrepancy in health outcomes (Government of Canada: Evaluation of the Federal Tobacco Control Strategy 2017; Jetty 2017). To better reflect the reality of the Canadian Indigenous population in the AppEco model, prevalence rates and all-cause mortality rates were adjusted. In doing so, the model is better equipped to inform policymakers on the potential health and cost impacts of VNP use amongst First Nations, Inuit and Métis, as it reflects more closely the reality on the ground (Feir and Akee 2019). These findings suggest that similar realities may be observed in adults of low socio-economic status, and individuals suffering with mental illnesses for instance, who are particularly vulnerable to disease and death related to cigarette smoking (Glover et al. 2020).

\section{Limitations}

With respect to the subgroups studied, limitations related to administrative data are present. CTADS does not cover the Yukon, Northwest Territories and Nunavut. Although the territories represent a small sample of the Canadian population, vaping and smoking prevalence data from these regions would have strengthened territorial-level results of the study. Furthermore, CTADS data pertains to all VNP products used by the population, whether regulated or not. We therefore could not account for the differences in health risks between regulated and unregulated products based on the available data. Additionally, smoking, and vaping prevalence rates, which were based on the six definitions smoking/vaping states, do not account for use frequency. The model, therefore, does not account for the actual number of times smokers smoke and VNP users vape per day, which may be associated with the modelled impact. While the model considers the decline of relative risks over time for former smokers, it does not account for smoking or vaping history pre-2015. As a result, relative risks at the onset of the study are based strictly on observed smoking or vaping states in 2015, without accounting for the number of years during which individuals smoked or vaped, and how frequently.

As with all population health models, our results are sensitive to assumptions embedded within the model, as future impacts will depend on policies that Canada chooses to implement. The results of our study therefore represent the general orders of magnitude of the differences observed between scenarios, and not precise point estimates. Lastly, as vaping technologies are disruptive in nature, knowledge about parameters surrounding its use is still accumulating. As 
mentioned previously, the long-term effects of VNPs are not fully known, and further research is needed.

\section{Conclusions}

Based on these findings, wider use of VNPs among Canadian adult smokers was associated with improved health and health system cost outcomes. Scenarios with higher rates of vaping uptake by adult smokers estimated a reduction in the total amount of life-years lost and costs associated with SR disease and mortality. Increased accessibility of VNPs for adult smokers who seek an alternative to combustible cigarettes in Canada may generate net public-health gains and healthsystem cost savings. These projected health and economic consequences are sensitive to assumptions about accessibility and use by adult smokers and may vary by type of policy environment. These results suggest that public health authorities may benefit from exploring the use of these products as alternatives for smokers to improve individual and population-level outcomes.

\section{References}

1. Apelberg, B.J., Feirman, S.P., Salazar, E., Corey, C.G., Ambrose, B.K., Paredes, A., Richman, E., Verzi, S.J., Vugrin, E.D., Brodsky, N.S., \& Rostron, B.L. (2018). Potential Public Health Effects of Reducing Nicotine Levels in Cigarettes in the United States. N Engl J Med, 378(18), 1725-1733.

2. Barendregt, J.J., van Oortmarssen, G.J., Vos, T., \& Murray, C.J. (2003). A generic model for the assessment of disease epidemiology: the computational basis of DisMod II. Popul Health Metrics, https://doi.org/10.1186/1478-7954-1-4

3. Bellavance, F., Dionne, G., \& Lebeau, M. (2009). The value of a statistical life: a meta-analysis with a mixed effects regression model. J Health Econ, 28(2), 444-64.

4. Blakely, T., Cobiac, L.J., Cleghorn, C.L., Pearson, A.L., van der Deen, F.S., et al. (2016). Health, Health Inequality, and Cost Impacts of Annual Increases in Tobacco Tax: Multistate Life Table Modeling in New Zealand. PLOS Medicine, 13(12), e1002211.

5. Burden of Disease Epidemiology, Equity \& Cost-Effectiveness Programme (BODE $\left.{ }^{3}\right)$. (n.d.). https://www.otago.ac.nz/wellington/departments/publichealth/research/bode3/index.html. Accessed April 62020.

6. Cherng, S.T., Tam, J., Christine, P.J., Meza, R. (2016). Modeling the Effects of E-cigarettes on Smoking Behavior: Implications for Future Adult Smoking Prevalence. Epidemiology, 27(6), 819-826.

7. Coleman, B., Rostron, B., Johnson, S. E., Persoskie, A., Pearson, J., Stanton, C., Choi, K., Anic, G., Goniewicz, M. L., Cummings, K. M., Kasza, K. A., Silveira, M. L., Delnevo, C., Niaura, R., Abrams, D. B., Kimmel, H. L., Borek, N., Compton, W. M., \& Hyland, A. (2019). Transitions in electronic cigarette use among adults in the Population Assessment of Tobacco and Health (PATH) Study, Waves 1 and 2 (2013-2015). Tobacco Control, 28(1), 50-59.

8. Feir, D., \& Akee, R. (2019). First Peoples lost: Determining the state of status First Nations mortality in Canada using administrative data. Canadian Journal of Economics, 52(2), 490-525.

9. Glover, M., Patwardhan, P., \& Selket, K. (2020). Tobacco smoking in three "left behind" subgroups: indigenous, the rainbow community and people with mental health conditions. Drugs and Alcohol Today, 20(3), 263-281.

10. Government of Canada: Evaluation of the Federal Tobacco Control Strategy 2012-2013 to 2015-2016. (2017). https://www.canada.ca/en/health-canada/corporate/transparency/corporate-management- 
reporting/evaluation/2012-2013-2015-2016-federal-tobacco-control-strategy.html. Accessed April 62020.

11. Government of Canada: Vaping product regulations. (n.d) https://www.canada.ca/en/health-canada/services/smokingtobacco/vaping/product-safety-regulation.html. Accessed April 62020.

12. Henningfield, J. E., Higgins, S. T., \& Villanti, A. C. (2018). Are we guilty of errors of omission on the potential role of electronic nicotine delivery systems as less harmful substitutes for combusted tobacco use?. Preventive medicine, https://doi.org/10.1016/j.ypmed.2018.09.011

13. Holford, T. R., Levy, D. T., McKay, L. A., Clarke, L., Racine, B., Meza, R., Land, S., Jeon, J., \& Feuer, E. J. (2014). Patterns of birth cohort-specific smoking histories, 1965-2009. American journal of preventive medicine, 46(2), e31e37.

14. Hoogenveen, R.T., van Baal, P.H., Boshuizen, H.C., \& Feenstra, T.L. (2008). Dynamic effects of smoking cessation on disease incidence, mortality and quality of life: The role of time since cessation. Cost Eff Resour Alloc, https://doi.org/10.1186/1478-7547-6-1

15. Jetty R; Canadian Paediatric Society, First Nations, Inuit and Métis Health Committee, Ottawa, Ontario. (2017). Tobacco use and misuse among Indigenous children and youth in Canada. Paediatr Child Health, 22(7), 395-405.

16. Levy, D.T., Borland, R., Lindblom, E.N., et al. (2018). Potential deaths averted in USA by replacing cigarettes with ecigarettes. Tobacco Control. 27(1), 18-25.

17. Levy, D.T., Borland, R., Villanti, A.C., Niaura, R., Yuan, Z., Zhang, Y., Meza, R., Holford, T.R., Fong, G.T., Cummings, K.M., \& Abrams, D.B. (2017). The Application of a Decision-Theoretic Model to Estimate the Public Health Impact of Vaporized Nicotine Product Initiation in the United States. Nicotine Tob Res, 19(2), 149-159.

18. Levy, D. T., Cummings, K. M., Villanti, A. C., Niaura, R., Abrams, D. B., Fong, G. T., \& Borland, R. (2017). A framework for evaluating the public health impact of e-cigarettes and other vaporized nicotine products. Addiction, 112(1), 8-17.

19. Manzoli, L., Flacco, M.E., Ferrante, M., La Vecchia, C., Siliquini, R., Ricciardi, W., Marzuillo, C., Villari, P., Fiore, M. \& ISLESE Working Group. (2017). Cohort study of electronic cigarette use: effectiveness and safety at 24 months. Tobacco Control, 26(3), 284-292.

20. McNeill, A., Brose, L.S., Calder, R., Bauld, L. \& Robson, D. (2018). Evidence review of e-cigarettes and heated tobacco products 2018. A report commissioned by Public Health England. London, UK: Public Health England.

21. National Academies of Sciences, Engineering, and Medicine; Health and Medicine Division; Board on Population Health and Public Health Practice; Committee on the Review of the Health Effects of Electronic Nicotine Delivery Systems; Eaton, D.L., Kwan, L.Y., Stratton, K., editors. (2018). Public Health Consequences of E-Cigarettes. Washington DC, US: National Academies Press.

22. Olsson, U. (2005). Confidence Intervals for the Mean of a Log-Normal Distribution, Journal of Statistics Education, https://doi.org/10.1080/10691898.2005.11910638

23. Paradis, P.E., Mishagina, N., Carter, V., \& Raymond, V. (2012). Economic impact of delays in listing decisions by provincial drug plans after a positive Common Drug Review recommendation: the case of a smoking-cessation treatment. Healthc Q, 15(2), 52-60.

24. Petrović-van der Deen, F.S., Wilson, N., Crothers, A., Cleghorn, C.L., Gartner, C., \& Blakely, T. (2019). Potential Country-level Health and Cost Impacts of Legalizing Domestic Sale of Vaporized Nicotine Products. Epidemiology, 
30(3), 396-404.

25. Ratajczak, A., Feleszko, W., Smith, DM., \& Goniewicz, M. (2018). How close are we to definitively identifying the respiratory health effects of e-cigarettes? Expert Rev Respir Med, 12(7), 549-556.

26. Stephens, W.E. (2018). Comparing the cancer potencies of emissions from vapourised nicotine products including ecigarettes with those of tobacco smoke. Tobacco Control, 27(1), 10-17.

27. Warner, K.E., \& Mendez, D. (2019). E-cigarettes: Comparing the Possible Risks of Increasing Smoking Initiation with the Potential Benefits of Increasing Smoking Cessation. Nicotine Tob Res. 21(1), 41-47.

28. Zhu, S-H., Zhuang, Y-L., Wong, S., Cummins, S.E., \& Tedeschi, G.J. (2017). E-cigarette use and associated changes in population smoking cessation: evidence from US current population surveys. BMJ, https://doi.org/10.1136/bmi.j3262

\section{Tables}

\section{Table 1. Data sources}

\begin{tabular}{|c|c|c|c|c|}
\hline Data element & $\begin{array}{l}\text { Granularity: } \\
\text { Canada, } \\
\text { Provinces } \\
\text { (P), } \\
\text { Territories } \\
\text { (T) }\end{array}$ & Source & $\begin{array}{l}\text { Time } \\
\text { Period }\end{array}$ & Notes \\
\hline Demographics & $\mathrm{P} / \mathrm{T}$ & $\begin{array}{l}\text { Statistics Canada, Table: } 17-10-0005-01 \\
\text { Census Aboriginal Population Profile }\end{array}$ & $\begin{array}{l}2015- \\
2016\end{array}$ & Population by age group and sex \\
\hline Mortality rates & $\mathrm{P} / \mathrm{T}$ & $\begin{array}{l}\text { Statistics Canada, Table: 13-10-0392-01; Table: 13-10-0710-01 } \\
\text { Donna Feir \& Randall Akee, 2018. "First People Lost: Determining the State } \\
\text { of Status First Nations Mortality in Canada Using Administrative Data," } \\
\text { Department Discussion Papers 1802, Department of Economics, University } \\
\text { of Victoria. }\end{array}$ & $\begin{array}{l}2015- \\
2017\end{array}$ & Mortality rates by age group and sex \\
\hline $\begin{array}{l}\text { Baseline rates } \\
\text { - smoking, } \\
\text { vaping, non- } \\
\text { smoking }\end{array}$ & $\mathrm{P}$ & Health Canada, Canadian Tobacco, Alcohol and Drugs (CTADS) Survey & $\begin{array}{l}2013 \\
2015 \\
\text { and } \\
2017\end{array}$ & $\begin{array}{l}\text { Special request placed to Statistics } \\
\text { Canada for aggregate compilations } \\
\text { of CTADS based on study } \\
\text { definitions }\end{array}$ \\
\hline $\begin{array}{l}\text { Transition } \\
\text { probabilities- } \\
\text { uptake and } \\
\text { cessation }\end{array}$ & $\mathrm{P}$ & $\begin{array}{l}\text { Health Canada, Canadian Tobacco, Alcohol and Drugs (CTADS) Survey } \\
\text { Holford TR et al. Patterns of Birth Cohort-Specific Smoking Histories, 1965- } \\
\text { 2009. Am J Prev Med. } 2014 \text { February; } 46(2): \text { e31-e37. } \\
\text { Zhu SH et al. E-cigarette use and associated changes in population } \\
\text { smoking cessation: evidence from US current population surveys. BMJ } \\
\text { 2017;358:j3262. } \\
\text { Manzoli et al. Cohort study of electronic cigarette use: effectiveness and } \\
\text { safety at } 24 \text { months. Tob Control 2017;26:284-292. }\end{array}$ & $\begin{array}{l}\text { Various } \\
\text { years }\end{array}$ & Modeled using economic literature \\
\hline $\begin{array}{l}\text { Disease- } \\
\text { specific } \\
\text { incidence } \\
\text { (base rates) }\end{array}$ & $\mathrm{P} / \mathrm{T}$ & $\begin{array}{l}\text { Statistics Canada, Table: 13-10-0111-01; Canadian Chronic Disease } \\
\text { Surveillance System (CCDSS) }\end{array}$ & $\begin{array}{l}2015- \\
2017\end{array}$ & $\begin{array}{l}\text { Smoking-related diseases } \\
\text { (recognized by Government of } \\
\text { Canada) }\end{array}$ \\
\hline $\begin{array}{l}\text { Disease- } \\
\text { specific } \\
\text { prevalence } \\
\text { (base rates) }\end{array}$ & Canada & $\begin{array}{l}\text { Statistics Canada Table: 13-10-0096-01; Table: 13-10-0158-01; Canadian } \\
\text { Cancer Registry (CCR); Public Health Agency of Canada (PHAC), } \\
\text { Canadian Chronic Disease Surveillance System (CCDSS) }\end{array}$ & $\begin{array}{l}2015- \\
2017\end{array}$ & $\begin{array}{l}\text { CCS annual report is produced in } \\
\text { collaboration with Statistics Canada } \\
\text { and the Public Health Agency of } \\
\text { Canada and provincial and } \\
\text { territorial cancer registries }\end{array}$ \\
\hline $\begin{array}{l}\text { Disease- } \\
\text { specific } \\
\text { mortality rates }\end{array}$ & Canada & Statistics Canada, Table: 13-10-0394-01; Table: 13-10-0782-01 & $\begin{array}{l}2015- \\
2017\end{array}$ & \\
\hline
\end{tabular}




\begin{tabular}{|c|c|c|c|c|}
\hline $\begin{array}{l}\text { RR of current } \\
\text { smokers vs } \\
\text { non-smokers } \\
\text { and former } \\
\text { smokers vs } \\
\text { non-smokers }\end{array}$ & $\begin{array}{l}\text { Canada and } \\
\text { international }\end{array}$ & $\begin{array}{l}\text { Gandini, S., Botteri, E., lodice, S., Boniol, M., Lowenfels, A.B., Maisonneuve, } \\
\text { P., Boyle, P.,2008. Tobacco smoking and cancer: a meta-analysis. Int. J. } \\
\text { Cancer 122, 155-164. } \\
\text { Manuel DG, Tuna M, Perez R, Tanuseputro P, Hennessy D, Bennett C, et } \\
\text { al. (2015) Predicting Stroke Risk Based on Health Behaviours: } \\
\text { Development of the Stroke Population Risk Tool (SPoRT). PLoS ONE } \\
\text { 10(12): e0143342. doi:10.1371/ journal.pone.0143342 } \\
\text { Osman S, Ziegler C, Gibson R, Mahmood R, Moraros J. The association } \\
\text { between risk factors and chronic obstructive pulmonary disease in Canada: } \\
\text { A cross-sectional study using the 2014 Canadian Community Health } \\
\text { Survey. Int J Prev Med 2017;8:86. } \\
\text { Statistics Canada, Catalogue no. } 82-003-X \text { • Health Reports, Vol. 24, no. 2, } \\
\text { pp. 12-22, February 2013: Smoking, smoking cessation and heart disease } \\
\text { risk: A 16-year follow-up study } \\
\text { Colamesta, V., D'Aguanno, S., Breccia, M., Bruffa, S., Cartoni, C., La Torre, } \\
\text { G., } 2016 \text {. Do the smoking intensity and duration, the years since quitting, the } \\
\text { methodological quality and the year of publication of the studies affect the } \\
\text { results of the meta-analysis on cigarette smoking and Acute Myeloid } \\
\text { Leukemia (AML) in adults? Crit. Rev. Oncol. Hematol. 99, 376-388. }\end{array}$ & $\begin{array}{l}2008- \\
2019\end{array}$ & $\begin{array}{l}\text { Primary source for most RRs: } \\
\text { Poirier et. al. (2019). Estimates of } \\
\text { the current and future burden of } \\
\text { cancer attributable to active and } \\
\text { passive tobacco smoking in } \\
\text { Canada. Preventive Medicine. } 122 \text {. } \\
\text { 9-19. 10.1016/j.ypmed.2019.03.015. }\end{array}$ \\
\hline $\begin{array}{l}\text { RR decay } \\
\text { effects and } \\
\text { time lags }\end{array}$ & Canada & $\begin{array}{l}\text { Hoogenveen RT et al. Dynamic effects of smoking cessation on disease } \\
\text { incidence, mortality and quality of life: The role of time since cessation. Cost } \\
\text { Eff Resour Alloc } 2008 \text {. }\end{array}$ & $\mathrm{n} / \mathrm{a}$ & \\
\hline $\begin{array}{l}\text { Disease } \\
\text { healthcare } \\
\text { costs }\end{array}$ & $\mathrm{P} / \mathrm{T}$ & $\begin{array}{l}\text { Statistics Canada, Table: 18-10-0005-01; Canadian Institute for Health } \\
\text { Information (CIHI) National Expenditure Trends; Statistics Canada, Public } \\
\text { Health Agency of Canada (PHAC), Economic Burden of IlIness in Canada } \\
\text { (EBIC). }\end{array}$ & $\begin{array}{l}2010- \\
2018\end{array}$ & \\
\hline
\end{tabular}

Table 2. Definitions of Smoking/Vaping States

Based on 2015 questions/definitions of the Canadian Tobacco, Alcohol and Drugs Survey (CTADS) 


\section{Smoking Vaping States}

Current Smoker and Not Current Vaper (CSNV)

Former Smoker and Not current Vaper (FSNV)

Never Smoker and Not Current Vaper (NSNV)

Dual User (DU)

Former Smoker and Current Vaper (FSCV)

Never Smoker and Current Vaper (NSCV)

\section{Canadian Tobacco Alcohol and Drugs Survey 2015} Survey Questions and Answers

1) At the present time, do you smoke cigarettes everyday, occasionally or not at all? A: Everyday, Occasionally

2) At the present time, do you use an electronic cigarette also known as an e-cigarette everyday, occasionally or not at all? A: Not at all

1) At the present time, do you smoke cigarettes everyday, occasionally or not at all? A: Not at all

2) Have you smoked at least 100 cigarettes in your life? A: Yes

3) At the present time, do you use an electronic cigarette also known as an e-cigarette everyday, occasionally or not at all? A: Not at all

1) At the present time, do you smoke cigarettes everyday, occasionally or not at all? A: Not at all

2) Have you smoked at least 100 cigarettes in your life? A: No

3) At the present time, do you use an electronic cigarette also known as an e-cigarette everyday, occasionally or not at all? A: Not at all

1) At the present time, do you smoke cigarettes everyday, occasionally or not at all? A: Everyday, Occasionally 2) At the present time, do you use an electronic cigarette also known as an e-cigarette everyday, occasionally or not at all? A: Everyday, Occasionally

1) At the present time, do you smoke cigarettes everyday, occasionally or not at all? A: Not at all

2) Have you smoked at least 100 cigarettes in your life? A: Yes

3) At the present time, do you use an electronic cigarette also known as an e-cigarette everyday, occasionally or not at all? A: Everyday, Occasionally

1) At the present time, do you smoke cigarettes everyday, occasionally or not at all? A: Not at all

2) Have you smoked at least 100 cigarettes in your life? A: No

3) At the present time, do you use an electronic cigarette also known as an e-cigarette everyday, occasionally or not at all? A: Everyday, Occasionally

Source: Canadian Tobacco, Alcohol and Drugs Survey (CTADS), 2015

questionnaire. http://www23.statcan.gc.ca/imdb/p3Instr.pl?Function=assemblelnstr\&a=1\&\&lang=en\&ltem_ld=299300.

Accessed September 5, 2019.

Table 3. Life years lost due to smoking-related (SR) diseases; incremental social cost (value) of life years lost, and cumulative total health and productivity costs (value)

\section{SQ, NV and PSP scenarios*}




\begin{tabular}{|c|c|c|c|c|c|c|c|}
\hline & & & & $\mathrm{SQ}-\mathrm{NV}$ & & SQ - PSP & \\
\hline & SQ & NV & PSP & Var. & $\%$ & Var. & $\%$ \\
\hline Life years lost due to SR diseases & 51169550 & 52092097 & 50451413 & -922547 & $1,8 \%$ & 718137 & $1,4 \%$ \\
\hline Social cost of life years lost due to SR diseases & $0 \$$ & $\begin{array}{l}36901884999 \\
\$\end{array}$ & $\begin{array}{l}-28725482105 \\
\$\end{array}$ & $\begin{array}{l}36901884 \\
999 \$\end{array}$ & -- & $\begin{array}{l}-28725482 \\
105 \$\end{array}$ & -- \\
\hline $\begin{array}{l}\text { Cumulative total health and mortality } \\
\text { (productivity) costs }\end{array}$ & $\begin{array}{l}178968059 \\
651 \$\end{array}$ & $\begin{array}{l}181092260 \\
198 \$\end{array}$ & $\begin{array}{l}177300651 \\
981 \$\end{array}$ & $\begin{array}{l}2124200547 \\
\$\end{array}$ & $1,2 \%$ & $\begin{array}{l}-1667407670 \\
\$\end{array}$ & - \\
\hline Cumulative disease costs & $\begin{array}{l}173751591 \\
335 \$\end{array}$ & $\begin{array}{l}175825255 \\
451 \$\end{array}$ & $\begin{array}{l}172138297 \\
304 \$\end{array}$ & $\begin{array}{l}2073664117 \\
\$\end{array}$ & $1,2 \%$ & $\begin{array}{l}-1613294031 \\
\$\end{array}$ & - \\
\hline Cumulative mortality (productivity) costs & $5216468316 \$$ & $5267004747 \$$ & $5162354677 \$$ & $50536431 \$$ & $1,0 \%$ & $-54113639 \$$ & $\begin{array}{l}- \\
1,0 \%\end{array}$ \\
\hline Incremental cost (value) of SQ scenario & & & & $\begin{array}{l}39026085 \\
547 \$\end{array}$ & & $\begin{array}{l}-30392889 \\
775 \$\end{array}$ & \\
\hline
\end{tabular}

Notes: * Status quo scenario ("SQ"): current prevalence and transition rates of smoking and vaping, and current regulatory environment as of Aug. 1st, 2019; No vaping scenario ("NV"): vaping does not exist, only three individual states (current, former, or never smoker), current regulatory environment; and Pro-Switching Policy scenario ("PSP"): hypothetical test of increased vaping prevalence.

Table 4. Life years lost due to SR diseases; incremental social cost (value) of life years lost, and cumulative total health and productivity costs (value)

By sex and ethnicity - SQ, NV and PSP scenarios* 


\begin{tabular}{|c|c|c|c|c|c|c|}
\hline & \multicolumn{2}{|c|}{$\begin{array}{l}\text { Life years lost due to SR } \\
\text { diseases }\end{array}$} & \multicolumn{2}{|c|}{$\begin{array}{l}\text { Social cost (value) of life years lost due to SR } \\
\text { diseases }\end{array}$} & \multicolumn{2}{|c|}{$\begin{array}{l}\text { Cumulative total health and mortality (productivity) } \\
\text { costs (value) }\end{array}$} \\
\hline & SQ vs. NV & SQ vs. PSP & SQ vs. NV & SQ vs. PSP & SQ vs. NV & SQ vs. PSP \\
\hline \multicolumn{7}{|l|}{ Values } \\
\hline Total & -922547 & 718137 & $36901884999 \$$ & $-28725482105 \$$ & $2124200547 \$$ & $-1667407670 \$$ \\
\hline Men & -585890 & 495198 & 23435604268 \$ & -19807907935 \$ & $1446374830 \$$ & -1213509232 \$ \\
\hline Non-Indigenous & -569097 & 470114 & $22763892196 \$$ & -18804559536 \$ & $1412447605 \$$ & $-1164397115 \$$ \\
\hline Indigenous & -16793 & 25084 & $671712072 \$$ & -1003348399 \$ & $33927226 \$$ & $-49112117 \$$ \\
\hline Women & -336657 & 222939 & 13466280732 \$ & -8917574170 \$ & 677825717 \$ & $-453898437 \$$ \\
\hline Non-Indigenous & -325877 & 208220 & $13035076331 \$$ & $-8328789200 \$$ & $659713502 \$$ & -429949322 \$ \\
\hline Indigenous & -10780 & 14720 & $431204401 \$$ & $-588784970 \$$ & $18112215 \$$ & $-23949116 \$$ \\
\hline \multicolumn{7}{|l|}{$\begin{array}{l}\text { Percent } \\
\text { difference }\end{array}$} \\
\hline Total & $-1,8 \%$ & $1,4 \%$ & -- & -- & $-1,2 \%$ & $0,9 \%$ \\
\hline Men & $-1,9 \%$ & $1,6 \%$ & -- & -- & $-1,3 \%$ & $1,1 \%$ \\
\hline Non-Indigenous & $-1,9 \%$ & $1,6 \%$ & -- & -- & $-1,3 \%$ & $1,0 \%$ \\
\hline Indigenous & $-1,4 \%$ & $2,0 \%$ & -- & -- & $-1,0 \%$ & $1,4 \%$ \\
\hline Women & $-1,7 \%$ & $1,1 \%$ & -- & -- & $-1,1 \%$ & $0,7 \%$ \\
\hline Non-Indigenous & $-1,7 \%$ & $1,1 \%$ & -- & -- & $-1,1 \%$ & $0,7 \%$ \\
\hline Indigenous & $-1,3 \%$ & $1,8 \%$ & -- & -- & $-0,8 \%$ & $1,1 \%$ \\
\hline
\end{tabular}

Table 5. Monte Carlo simulations ( $N=1,000)$ for cohort of non-Indigenous men aged 30-34 in 2015

$S Q$ vs. NV, and SQ vs. PSP scenarios 
Scenario comparison

SQ - NV
Life years lost due to SR diseases
Social cost of life years lost due to SR diseases
Cumulative total health and mortality (productivity) costs
Cumulative disease costs
Cumulative mortality (productivity) costs
Incremental cost (value) of SQ vs. NV scenario

SQ - PSP

Life years lost due to SR diseases

Social cost of life years lost due to SR diseases

Cumulative total health and mortality (productivity) costs

Cumulative disease costs

Cumulative mortality (productivity) costs

Incremental cost (value) of SQ vs. PSP scenario
Results

$-64792$

$2591666083 \$$

156773939 \$

$150902408 \$$

$5871531 \$$

2748440021 \$
Monte Carlo simulations $(\mathrm{N}=1,000)$

95\% confidence interval

Mean

Lower bound Upper bound

$-64571$

$-82993$

$-48280$

$2582826680 \$$

3319708881 \$ 1931200401 \$

$156085679 \$$

205035287 \$

$113950036 \$$

$150231717 \$$

197157920 \$

109770965 \$

$5853962 \$$

7877367 \$

4179071 \$

2738912359 \$

3524744168 \$

2045150437 \$

\begin{tabular}{|l|l|l|l|}
\hline 49332 & 49171 & 36659 & 63370 \\
\hline$-1973267861 \$$ & $-1966835557 \$$ & $-1466375589 \$$ & $-2534787791 \$$ \\
\hline$-134052558 \$$ & $-133517678 \$$ & $-95446974 \$$ & $-178903567 \$$ \\
\hline$-126431621 \$$ & $-125919641 \$$ & $-90064844 \$$ & $-168624480 \$$ \\
\hline$-7620937 \$$ & $-7598037 \$$ & $-5382130 \$$ & $-10279087 \$$ \\
\hline$-2107320419 \$$ & $-2100353235 \$$ & $-1561822563 \$$ & $-2713691358 \$$ \\
\hline
\end{tabular}

49332

$2100353235 \$$

Note: Simulations were performed on risk ratios of contracting SR diseases for every smoking/vaping state and disease, using log-normal distributions and confidence intervals published in literature. Results column used mean values for all inputs.

\section{Figures}

Figure 1. Structure of the AppEco multi-state life-table model 
ther characteristic

Cohorts are simulated one at a time; sex (men, women), ethnidity (non-Indgenous and indigenous), and age (20-24, 25-29, ..., 95-99).

The main life-table depicted above is for simulaton 1, performed at mean values for all inputs. For Nonte-Carlo simulations, the model has been "stacked" on a single column,

and replicated to generate the 1,000 simulations.

Although this study presents results for all of Canada, the AppEco model is suilt to simulate outcomes for any combination of province(s) and territorie(s)

Legend:

$\rightarrow$ The data sources listed were used as inputs for the main lifetable.

$\mathrm{SQ}=$ Status Quo scenario

$\mathrm{NV}=$ No-Vaping Scenario

PSP $=$ Pro-Switching Policy scenario

CSNV = Current Smokers and Not Current Vaper

DU = Dual User

FSCV $=$ Former Smoker and Current Vaper

NSNV = Never Smoker and Not Current Vaper

FSCV $=$ Former Smoker and Current Vaper

NSCV $=$ Never Smoker and Current Vaper

$\mathrm{RR}=$ Risk ratio

$\mathrm{N}$ of deaths $=$ Number of deaths

$\mathrm{SR}=$ Smoking-related

Figure 2. Transition Matrices

SQ, NV and PSP scenarios* 
SQ and PSP Scenarios

Transition Matrix 20-44 years old

\begin{tabular}{|c|c|c|c|c|c|c|}
\hline & CSNV & DU & FSCV & NSCV & FSNV & NSNV \\
\hline CSNV & $96,0 \%$ & $0,0 \%$ & $0,4 \%$ & $0,0 \%$ & $3,6 \%$ & $0,0 \%$ \\
\hline DU & $6,8 \%$ & $86,3 \%$ & $1,3 \%$ & $0,0 \%$ & $5,5 \%$ & $0,0 \%$ \\
\hline FSCV & $0,0 \%$ & $0,0 \%$ & $96,0 \%$ & $0,0 \%$ & $4,0 \%$ & $0,0 \%$ \\
\hline NSCV & $0,0 \%$ & $0,0 \%$ & $0,0 \%$ & $96,0 \%$ & $0,0 \%$ & $4,0 \%$ \\
\hline FSNV & $0,0 \%$ & $0,0 \%$ & $0,0 \%$ & $0,0 \%$ & $100,0 \%$ & $0,0 \%$ \\
\hline NSNV & $0,0 \%$ & $0,0 \%$ & $0,0 \%$ & $0,0 \%$ & $0,0 \%$ & $100,0 \%$ \\
\hline
\end{tabular}

Transition Matrix 45-64 years old

\begin{tabular}{|c|c|c|c|c|c|c|}
\hline & CSNV & DU & FSCV & NSCV & FSNV & NSNV \\
\hline CSNV & $95,8 \%$ & $0,0 \%$ & $0,4 \%$ & $0,0 \%$ & $3,8 \%$ & $0,0 \%$ \\
\hline DU & $7,2 \%$ & $85,6 \%$ & $1,4 \%$ & $0,0 \%$ & $5,8 \%$ & $0,0 \%$ \\
\hline FSCV & $0,0 \%$ & $0,0 \%$ & $95,8 \%$ & $0,0 \%$ & $4,2 \%$ & $0,0 \%$ \\
\hline NSCV & $0,0 \%$ & $0,0 \%$ & $0,0 \%$ & $95,8 \%$ & $0,0 \%$ & $4,2 \%$ \\
\hline FSNV & $0,0 \%$ & $0,0 \%$ & $0,0 \%$ & $0,0 \%$ & $100,0 \%$ & $0,0 \%$ \\
\hline NSNV & $0,0 \%$ & $0,0 \%$ & $0,0 \%$ & $0,0 \%$ & $0,0 \%$ & $100,0 \%$ \\
\hline
\end{tabular}

Transition Matrix 65+ years old

\begin{tabular}{|c|c|c|c|c|c|c|}
\hline & CSNV & DU & FSCV & NSCV & FSNV & NSNV \\
\hline CSNV & $94,0 \%$ & $0,0 \%$ & $0,6 \%$ & $0,0 \%$ & $5,4 \%$ & $0,0 \%$ \\
\hline DU & $0,0 \%$ & $89,7 \%$ & $2,0 \%$ & $0,0 \%$ & $8,3 \%$ & $0,0 \%$ \\
\hline FSCV & $0,0 \%$ & $0,0 \%$ & $94,0 \%$ & $0,0 \%$ & $6,0 \%$ & $0,0 \%$ \\
\hline NSCV & $0,0 \%$ & $0,0 \%$ & $0,0 \%$ & $94,0 \%$ & $0,0 \%$ & $6,0 \%$ \\
\hline FSNV & $0,0 \%$ & $0,0 \%$ & $0,0 \%$ & $0,0 \%$ & $100,0 \%$ & $0,0 \%$ \\
\hline NSNV & $0,0 \%$ & $0,0 \%$ & $0,0 \%$ & $0,0 \%$ & $0,0 \%$ & $100,0 \%$ \\
\hline
\end{tabular}

NV Scenario

Transition Matrix 20-44 years old

\begin{tabular}{|c|c|c|c|c|c|c|}
\hline & CSNV & DU & FSCV & NSCV & FSNV & NSNV \\
\hline CSNV & $96,8 \%$ & $0,0 \%$ & $0,0 \%$ & $0,0 \%$ & $3,2 \%$ & $0,0 \%$ \\
\hline DU & $0,0 \%$ & $0,0 \%$ & $0,0 \%$ & $0,0 \%$ & $0,0 \%$ & $0,0 \%$ \\
\hline FSCV & $0,0 \%$ & $0,0 \%$ & $0,0 \%$ & $0,0 \%$ & $0,0 \%$ & $0,0 \%$ \\
\hline NSCV & $0,0 \%$ & $0,0 \%$ & $0,0 \%$ & $0,0 \%$ & $0,0 \%$ & $0,0 \%$ \\
\hline FSNV & $0,0 \%$ & $0,0 \%$ & $0,0 \%$ & $0,0 \%$ & $100,0 \%$ & $0,0 \%$ \\
\hline NSNV & $0,0 \%$ & $0,0 \%$ & $0,0 \%$ & $0,0 \%$ & $0,0 \%$ & $100,0 \%$ \\
\hline
\end{tabular}

Transition Matrix 45-64 years old

\begin{tabular}{|c|c|c|c|c|c|c|}
\hline & CSNV & DU & FSCV & NSCV & FSNV & NSNV \\
\hline CSNV & $96,6 \%$ & $0,0 \%$ & $0,0 \%$ & $0,0 \%$ & $3,4 \%$ & $0,0 \%$ \\
\hline DU & $0,0 \%$ & $0,0 \%$ & $0,0 \%$ & $0,0 \%$ & $0,0 \%$ & $0,0 \%$ \\
\hline FSCV & $0,0 \%$ & $0,0 \%$ & $0,0 \%$ & $0,0 \%$ & $0,0 \%$ & $0,0 \%$ \\
\hline NSCV & $0,0 \%$ & $0,0 \%$ & $0,0 \%$ & $0,0 \%$ & $0,0 \%$ & $0,0 \%$ \\
\hline FSNV & $0,0 \%$ & $0,0 \%$ & $0,0 \%$ & $0,0 \%$ & $100,0 \%$ & $0,0 \%$ \\
\hline NSNV & $0,0 \%$ & $0,0 \%$ & $0,0 \%$ & $0,0 \%$ & $0,0 \%$ & $100,0 \%$ \\
\hline
\end{tabular}

Transition Matrix 65+ years old

\begin{tabular}{|c|c|c|c|c|c|c|}
\hline & CSNV & DU & FSCV & NSCV & FSNV & NSNV \\
\hline CSNV & $95,2 \%$ & $0,0 \%$ & $0,0 \%$ & $0,0 \%$ & $4,8 \%$ & $0,0 \%$ \\
\hline DU & $0,0 \%$ & $0,0 \%$ & $0,0 \%$ & $0,0 \%$ & $0,0 \%$ & $0,0 \%$ \\
\hline FSCV & $0,0 \%$ & $0,0 \%$ & $0,0 \%$ & $0,0 \%$ & $0,0 \%$ & $0,0 \%$ \\
\hline NSCV & $0,0 \%$ & $0,0 \%$ & $0,0 \%$ & $0,0 \%$ & $0,0 \%$ & $0,0 \%$ \\
\hline FSNV & $0,0 \%$ & $0,0 \%$ & $0,0 \%$ & $0,0 \%$ & $100,0 \%$ & $0,0 \%$ \\
\hline NSNV & $0,0 \%$ & $0,0 \%$ & $0,0 \%$ & $0,0 \%$ & $0,0 \%$ & $100,0 \%$ \\
\hline
\end{tabular}

* Notes: Transition probabilities for SQ and PSP scenarios are assumed equal. For these scenarios the following smoking cessation rates, based on results obtained by Holford et al., were used to estimate the transition probability for each cohort: $20-44=4 \%, 45-64=4.2 \%$, and $65+=6 \%$. Smoking cessation rates used for DUs were based on the results of Zhu et al.: $20-44=6.8 \% ; 45-64=7.2 \%$; and $65+=10.3 \%$. These rates were also used as smoking uptake rates for DUs who revert to smoking, per the findings of Coleman et al. In SQ and PSP scenario, individuals moving from CSNV to FSCV and DU to FSCV were based on the results of Manzoli et al. The remaining transition probabilities were estimated using the residual sum of the initial probabilities (ex. CSNV to FSNV for the 20-44 age cohort $=1-$ CSNV to CSNV (\%) - CSNV to FSCV (\%) $=1-96.0 \%-0.4 \%=3.6 \%)$. To simulate a world without vaping, transitions for the NV scenario were derived by adjusting cessation results of Zhu et al. for the overall population (4.5\% for 2010-11 and 5.6\% for 2014-15). To do this, smoking cessation rates used in SQ and PSP scenarios for each cohort were multiplied by the overall population cessation for smokers 2010-11 / overall population cessation for smokers 2014-15: $20-44=3.2 \%, 45-64=3.4 \%$, and $65+=3.8 \%$. For all scenarios, in the cases where only one possible transition exists (e.g. NSNV to NSNV or FSNV to FSNV), the transition rate was set at $100 \%$.

Figure 3. Total incremental costs (value), by sex and ethnicity

\section{a. NV vs. SQ scenarios}




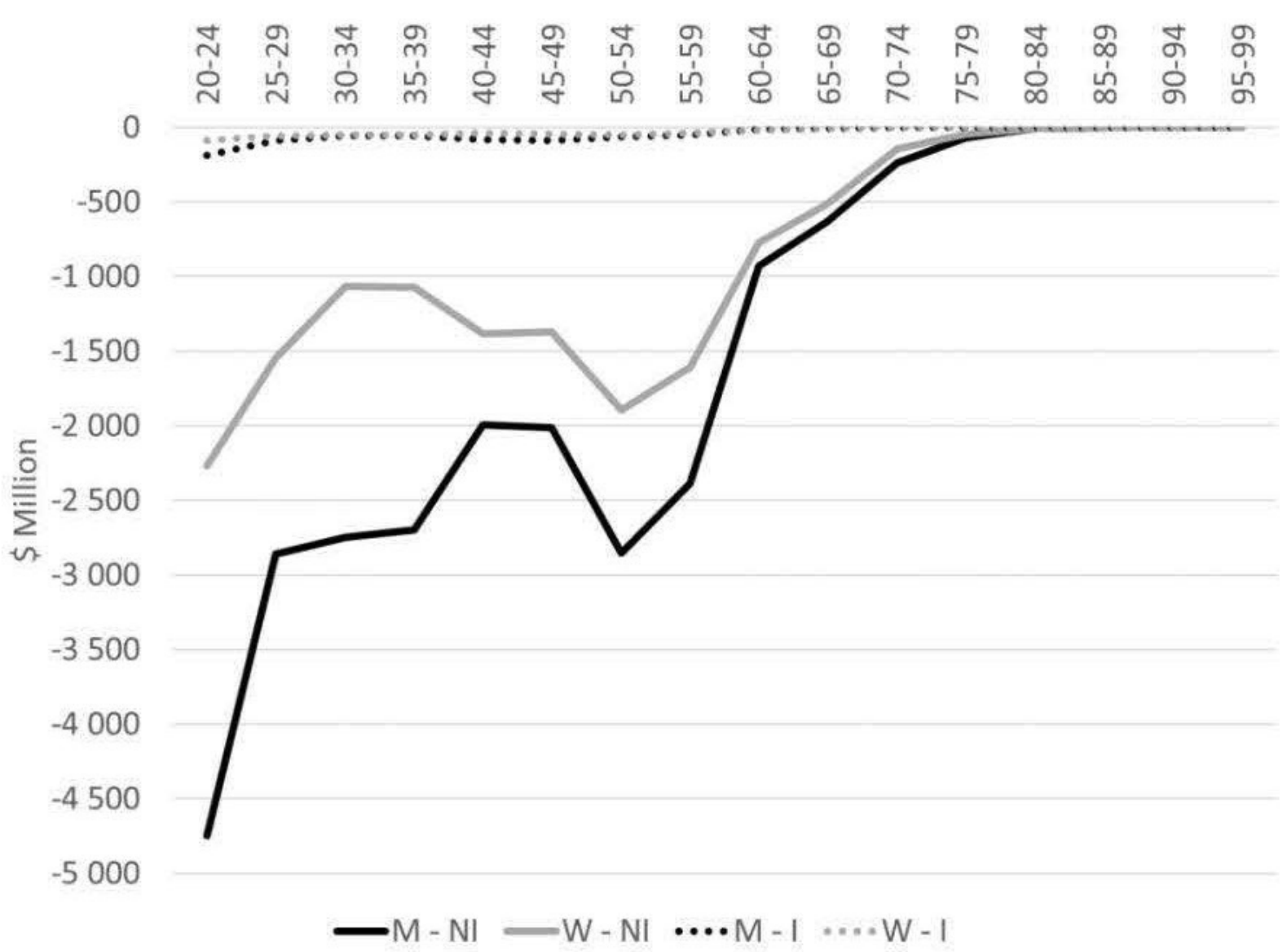

b. PSP vs SQ scenarios 6000

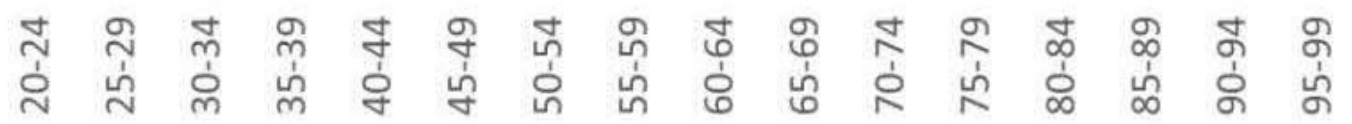

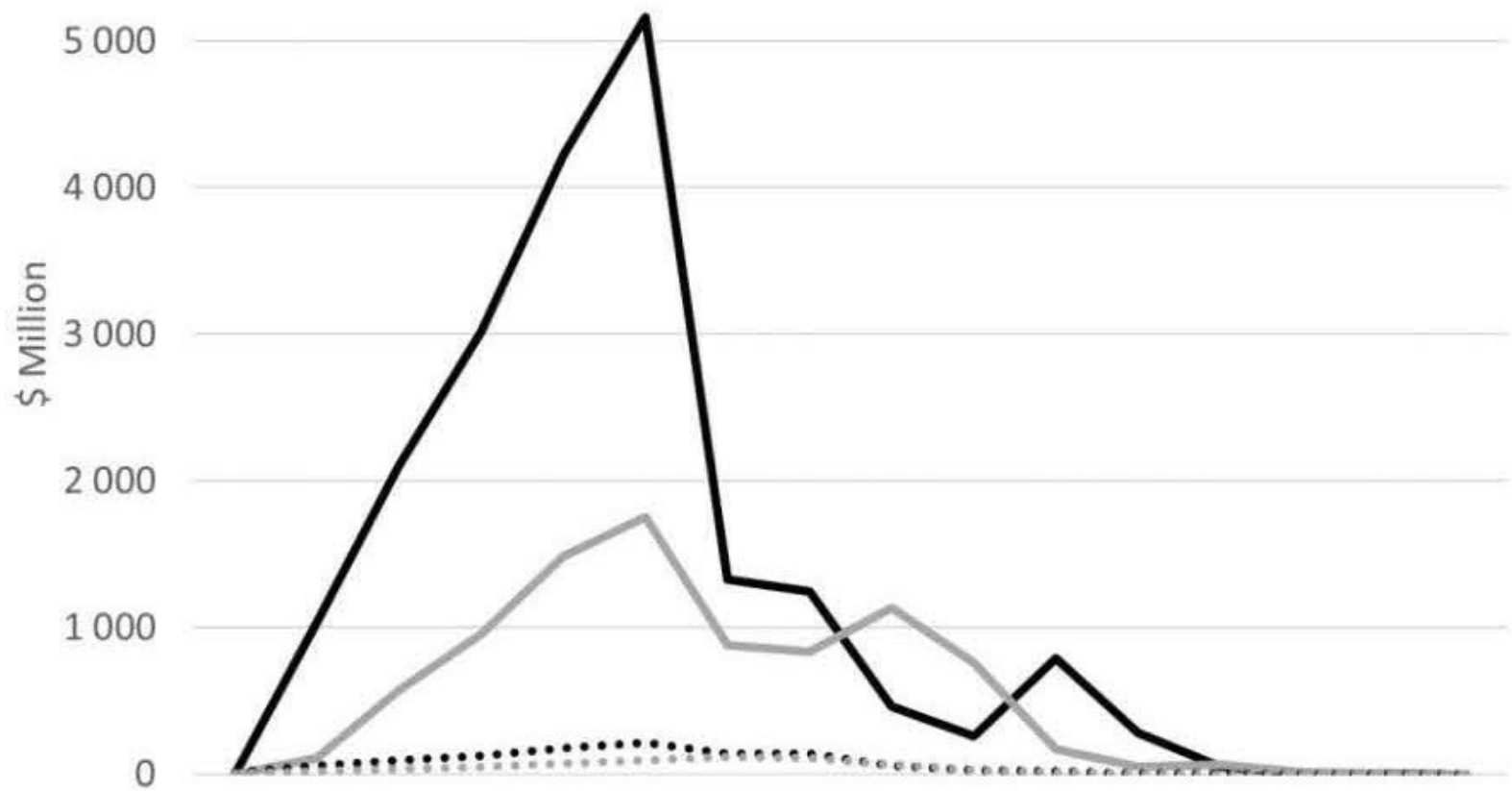




$$
-\mathrm{M}-\mathrm{NI} \longrightarrow \mathrm{W}-\mathrm{NI} \cdots \mathrm{M}-\mathrm{I} \cdots \mathrm{W}-\mathrm{I}
$$

Legend:

$\mathrm{SQ}=$ Status Quo scenario

NV = No-Vaping Scenario

PSP $=$ Pro-Switching Policy scenario

$\mathrm{M}=$ Men

$\mathrm{W}=$ Women

$\mathrm{NI}=$ Non-Indigenous

$\mathrm{I}=$ Indigenous

Figure 4. Sensitivity analysis - Life years lost due to SR diseases

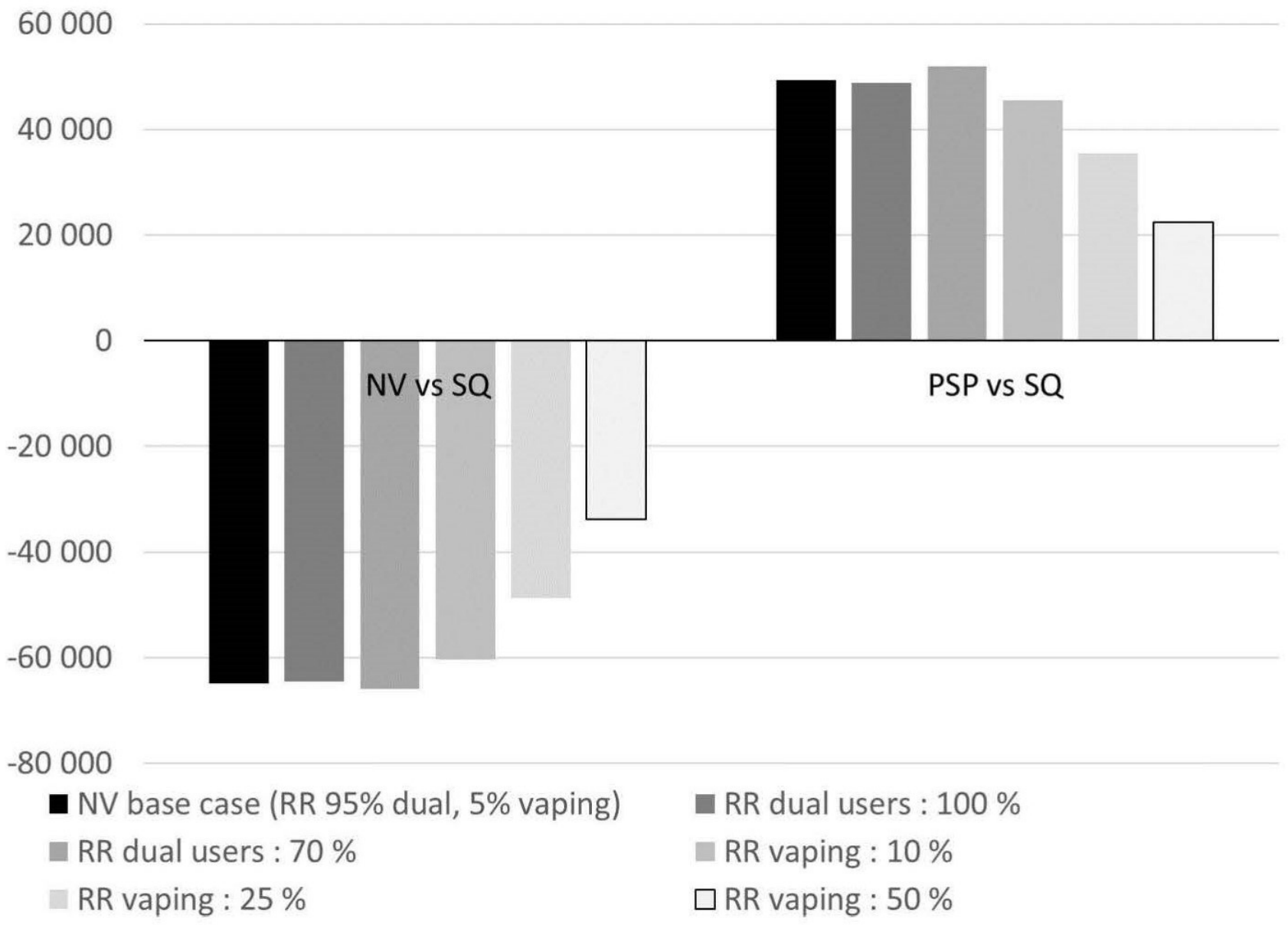

Legend:

$\mathrm{SR}=$ Smoking-related

$\mathrm{SQ}=$ Status Quo scenario

NV = No-Vaping Scenario 
PSP $=$ Pro-Switching Policy scenario

$\mathrm{RR}=$ Risk ratio 